\title{
Erratum
}

\section{Pregabalin-associated Elevation of Clozapine Serum Levels}

\section{Gahr, M. M. Schmid, C. Schönfeldt-Lecuona}

Pharmacopsychiatry 2012; Published online ahead of print: DOI: 10.1055/s-0032-1306312

This article was published with a misspellt word in title. Sarum was changed to Serum. 